\title{
Apuntes para una historia comparada de trayectorias episcopales durante el reinado de Felipe V (1701-174,6)
}

\author{
Notes for a comparative history of episcopal trajectories \\ during the reign of Philip V (1701-1746) \\ Alejandro Nicolás Chiliguay \\ ICSOH-CONICET \\ Univerisdad Nacional de Salta-ARGENTINA \\ alejandrochiliguay@yahoo.com
}

\section{Resumen}

Numerosos estudios se han realizado sobre trayectorias episcopales para elámbito de la Monarquía Hispánica, sin embargo, estos se han caracterizado por acotar sus objetos de estudio a un fragmento del marco territorial, a una figura en particular, o a la configuración de grupos entorno a un personaje articulador. Este trabajo pretende desarrollar una historia comparada de trayectorias de tres clérigos que lograron ser nombrados obispos. El objetivo es desarrollar, mediante el análisis de estos tres casos, un estudio que articule temática, temporal y territorialmente la diversidad de carreras episcopales acaecidas durante parte del reinado de Felipe V. De tal modo, se compararán las trayectorias del obispo de Cádiz Lorenzo Armengual de la Mota, y de los obispos del Tucumán Juan de Sarricolea y Olea, y José Antonio Gutiérrez de Zevallos, quienes estuvieron en función de sus promociones para las mitras castellanas e indianas entre los años 1716 y 1740.

Palabras clave: historia comparada, trayectorias, obispos, política eclesiástica, Felipe V.

\begin{abstract}
Numerous studies have been conducted on episcopal trajectories within the Spanish monarchy. Nevertheless, they are usually limited to one fragment of the territorial frame, one particular figure or on the configuration of groups around the centre person. This work seeks to develop a compared history of the trajectories of three clergymen who achieved to become a bishop. The purpose is to develop a study that articulates the diversity on a theme, time and territory of episcopal careers during a part of the reign of Philip V. We compare the careers of Lorenzo Armengual de la Mota (bishop of Cádiz), Juan de Sarricolea y Olea, y José Antonio Gutiérrez de Zevallos (bishops of Tucumán) based on their promotions for the
\end{abstract}

Alejandro Nicolás Chiliguay

Apuntes para una historia comparada de trayectorias episcopales durante el reinado de Felipe V (1701-1746) Autoctonía. Revista de Ciencias Sociales e Historia, Vol. IV, N 1 , Enero-Junio 2020, 44-64 ISSN 0719-8213

DOI: http://dx.doi.org/10.23854/autoc.v4il.152 
Castilian and Indian mitres between 1716 and 1740 .

Keywords: compared history, trajectories, bishops, ecclesiastical politics, Philip V.

Recibido: 21 de Junio de 2019 - Aceptado: 18 de Noviembre de 2019

\section{Introducción}

En las últimas décadas, a raíz del desmigajamiento de la historia, las investigaciones relativas a la historia de la Iglesia han experimentado una constante renovación a la luz del descubrimiento de nuevos objetos, campos y enfoques de estudio. Hoy, la Nueva Historia Política (Martínez Millán, 2011; Nieva Ocampo, 2016) en vinculación con la Nueva Historia Social (Aguirre Salvador, 2012) considera que los trabajos relativos a la Edad Moderna no deben prescindir en sus análisis de los aspectos religiosos, ya que constituyen un elemento omnipresente en la realidad social del Antiguo Régimen. En consecuencia, el estudio del clero tampoco debe escindirse de la sociedad en general, puesto que no constituyó un grupo cerrado y uniforme, sino más bien, uno heterogéneo, interrelacionado, inserto en las diversas sociabilidades y con múltiples intereses (Benito Aguado, 1994: 44). Por lo tanto, a partir de esta definición de los eclesiásticos como sujetos dinámicos, es posible estudiarlos como agentes políticos necesarios en el gobierno de la Monarquía. Desde este marco, propongo trabajar las trayectorias episcopales poniendo énfasis en la provisión episcopal y en el accionar político de los obispos, esto en el marco de las tensas relaciones entre Felipe V y el Papado tras la Guerra de Sucesión Española (1701-1714).
Si bien se han realizado numerosos estudios de las trayectorias episcopales para el ámbito de la Monarquía Hispánica durante la Edad Moderna, la mayor parte de los trabajos relativos al siglo XVIII se han centrado en los casos peninsulares (Morgado García, 2007: 80), con especial énfasis en los clérigos cortesanos (López Arandia, 2015). Rodolfo Aguirre Salvador sostiene que para el caso novohispano, el siglo XVII y la primera mitad de la centuria dieciochesca aún presentan lagunas en los conocimientos sobre los variados aspectos que atañen al clero. Para este autor, la razón de esta carencia reside en que:

normalmente se ha considerado como una continuación de los procesos de la centuria anterior, o bien, como la época que simplemente antecedió el reinado de Carlos III (Aguirre Salvador, 2012: 16).

Tal afirmación puede ser extensible para los casos indianos en general, aunque, actualmente los vacíos están siendo subsanados para Nueva España por autores como Rodolfo Aguirre Salvador, Óscar Mazín, Gisela Von Wobeser y María del Pilar López Cano, y en el caso de Sudamérica, por los trabajos de Lucrecia Enríquez Agrazar, entre otros investigadores (Aguirre Salvador, 2012; Mazín, 1996; Von Wobeser, 1999; Martínez López Cano, 2017; Enríquez Agrazar, 2006). 
El periodo que se abordará en este artículo se caracteriza por importantes transformaciones en el ámbito político, económico y eclesiástico. Estos cambios derivaron, principalmente, del advenimiento de Felipe V de Borbón, ocurrido tras la Guerra de Sucesión Española, periodizada entre la constitución de la Gran Alianza de la Haya, en 1701, y la firma de los tratados de Utrecht, Rastaat y Baden, en 1713-1714 (Castro, 2004: 39; León Sanz, 2002: 56). La contienda bélica tuvo múltiples implicancias: significó, en primer lugar, una amputación territorial de la Monarquía Hispánica, a partir de la pérdida de Flandes, Milán, Nápoles, Sicilia, Cerdeña y Gibraltar); en segundo lugar, un condicionamiento comercial a partir de la concesión del navío de permiso y del Asiento de negros para Gran Bretaña; y, por último, un cambio en la política exterior, particularmente respecto al Papado, a raíz de los infructuosos intentos de Clemente XI (1700-1721) para erigirse como mediador en el conflicto, quien, sin embargo, cedió finalmente a la presión austríaca sobre Italia, que lo obligó a no reconocer la legitimidad de Felipe V como rey de España (Martín Marcos, 2011).

Por otro lado, en la península, la guerra permitió la abolición de la Corona de Aragón a través de los decretos de Nueva Planta, lo que significó un trastorno en el tradicional sistema agregativo de la Monarquía Hispana (Dedieu, 2000). En cuanto a las posesiones americanas, la Monarquía intentó implantar un proyecto de "monarquía bihemisférica”, que consistía en articular Indias con la península, para garantizar la integridad de España como potencia europea, al ser su principal proveedor de recursos. Todo se encaminaba a impulsar una mayor centralización de la administración (Guillamón Álvarez, 2010: 372).

Sin embargo, la aplicación del proyecto siguió dependiendo del sistema de negociación que los agentes del rey desplegaban con los patronos locales, así como del grado de integración de las elites locales al poder central (Dedieu, 2005). En este sentido, uno de los agentes que actuaron en pro de acrecentar el control político de la Corona en dichos territorios fueron los obispos, en su calidad de consejeros naturales (Mazín, 2012: 374). Los prelados eran necesarios para recomponer la autoridad real en aquellos lugares en que esta se vio disminuida como consecuencia de la guerra o a causa de la debilidad misma de la Monarquía.

A lo largo del artículo se tratará de demostrar la importancia que habría tenido la designación de obispos que respondiesen al proyecto político de la corona a partir de los diversos mecanismos que mediaron en su selección. En este sentido, se analizarán comparativamente las trayectorias que permitieron alcanzar una mitra a Lorenzo Armengual de la Mota, Juan de Sarricolea y Olea, y José Antonio Gutiérrez de Zevallos, prestando particular atención a sus orígenes sociales, su formación, los promotores de sus carreras y los méritos propios de cada uno.

\section{La provisión de los cargos episcopales en el marco de las tensas relaciones entre Madrid y Roma}

Los obispos eran funcionarios eclesiásticos con jerarquía de orden y jurisdicción, es decir, eran pastores espirituales de sus diócesis con la capacidad 
de poder administrar todos los sacramentos y a su vez, eran los administradores naturales de su obispado, ejerciendo el gobierno y la justicia, sobre todo en materia de disciplina. Los monarcas contaron desde el año 1508, para las iglesias en Indias, y desde 1523, para las castellanas y aragonesas, con una serie de regalías concedidas por el papado, más conocidas como Patronato Regio. En virtud de ellas, el rey gozaba del derecho de presentación de los obispos y dignidades, lo que permitió la configuración de un nuevo episcopado (Tedesco, et. al., 2005: 27; Morgado García, 2000: 35; Barrio Gozalo, 2017a: 21).

Ya desde el reinado de Felipe II (1556-1598) los monarcas se esforzaron por convertir al conjunto del episcopado en agentes de su política confesional y financiera, especialmente en los momentos de mayores tensiones políticas, bélicas y sociales (Fernández Terricabras, 2001: 208). De ahí el interés de la Corona en controlar las provisiones episcopales, que necesitaban del concurso final del pontífice romano. Sin embargo, a pesar de que el rey tenía el derecho de presentación, en realidad tan solo se limitaba a escoger entre un grupo de "episcopables" que la misma jerarquía eclesiástica se había encargado de formar, y que los consejeros, camaristas, confesores reales y secretarios se habían encargado de decantar a través de mecanismos formales e informales, mediante la vía ejecutiva y la reservada (Artola Renedo, 2013: 36).

La vía consultiva, ejecutiva u ordinaria para la provisión de obispados discurría por una serie de eslabones claramente establecidos. Un primer paso era la confección de listados con candidatos idóneos, elaborados en territorio ibérico y americano. En los dominios ibéricos de la Corona, durante los primeros años del reinado de Felipe V, el Consejo de Castilla y el de Aragón o sus respectivas Cámaras, solicitaban a los presidentes de las Chancillerías, a los virreyes, a los regentes de las Audiencias, al obispo de Sala manca y al abad de Alcalá de Henares, un informe de aquellas personas idóneas para ocupar una mitra en el reino. Sin embargo, tras la abolición del consejo territorial aragonés -el 7 de julio de 1707- por la implantación de los decretos de Nueva Planta, todos los negocios eclesiásticos del reino fueron incorporados al consejo castellano. En cuanto a los dominios americanos, el Consejo y la Cámara de Indias intervenían en el proceso mediante la consulta a los virreyes, prelados, gobernadores y demás autoridades solicitando informes sobre potenciales candidatos. A partir de esas informaciones, los consejos confeccionaban las ternas con los nombres de aquellas personas propuestas para que el monarca se pudiese servir para cubrir las vacantes.

Estas listas sugerían al rey un orden de prioridad entre los candidatos, que se establecían a partir de la pesquisa realizada sobre sus cursus honorum. Entre los datos que las cámaras requerían sobre las personas recomendadas, figuran "su edad, procedencia geográfica y puestos ocupados" (Morgado García, 2000: 65). En efecto, según los criterios tradicionales, los sujetos debían reunir una serie de calidades y méritos: como ser naturales de los reinos dela Corona, ser personas honestas-es decir, continentes en cuanto al pecunio y proclives a la tarea pastoral-, demostrar limpieza de sangre y ser letrados; puesto que el servicio real requería de 
personas virtuosas, cultas y competentes (Comella Gutiérrez, 2008: 707). Además, debido a la guerra y al cuestionamiento de la legitimidad de Felipe V de Borbón como rey de España, la fidelidad y defensa de la causa borbónica se convirtió en un "mérito añadido" (Barrio Gozalo, 2017a: 22)

Posteriormente, el rey, asesorado por su confesor, tomaba la última decisión antes de remitirla a Roma. Teófanes Egido señala la importancia que tuvo para la Compañía de Jesús el monopolio que ejercía sobre el confesionario regio durante el reinado de Felipe V, ya que del confesor dependía en gran medida la provisión de obispados, de beneficios, de canonjías y otras pretensiones que permitía ganar la voluntad de algunos a favor de los jesuitas (Egido, 2004: 234). El confesor real estudiaba y analizaba los informes que llegaban a su despacho, y aprovechaba la oportunidad de despachar a boca con rey para potenciar las cualidades de su candidato predilecto y lograr su elección. Gracias a la red de informantes que tenía desplegado a lo ancho de los territorios de la Corona, el confesor gozaba de un mapa privilegiado de las vacantes existentes y aquellas que se avizorasen próximas a estar disponibles, lo que le permitía no solo colaborar con la designación de la plaza inmediata a cubrir, sino que también podía proponer suplentes y diagramar futuras promociones. Por ejemplo, en el año 1714, el confesor Robinet había propuesto al arcediano de Saldaña, Antonio de Horcasitas y Avellaneda para el obispado de Calahorra, tras la muerte de su titular, Alonso de Mena y Borja. Horcasitas era tío del tesorero mayor de Guerra, conde de Moriana, un hombre fiel a Jean Orry, miembro del equipo francés al que pertenecía el confesor. A sabiendas de que el arcedianato de Saldaña quedaba vacante, Robinet despachó a boca con el rey la provisión de la dignidad en Francisco de Viergol y Vadillo, sobrino de Manuel Vadillo, secretario del Despacho Universal (Guerrero Elecalde, 2010: 49-50). Por lo tanto, por el alcance de su influencia, el confesor solía recibir de manera directa, sin intermediación de las Cámaras, relaciones de méritos e informes sobre sujetos proclives a ser beneficiado con alguna prebenda, para otorgar la plaza sin atender a los mecanismos formales en los que mediaban los consejos (Orrego González, 2017: 165).

A continuación, el candidato elegido era informado y se le solicitaba su aceptación, sin embargo, podía declinar de la propuesta. Una vez que la persona electa consentía la disposición real, se confeccionaba una Real Cédula de presentación. Mientras tanto, en Madrid, el nuncio apostólico ordenaba la realización del proceso consistorial, que consistía en la reunión de información a través de una serie de testigos convocados para dar cuenta del perfil del candidato y del estado de la diócesis que iba a gobernar. El cuarto paso estaba a cargo del embajador de España en Roma, que elevaba la propuesta a la Curia, en donde el Consistorio Secreto-formado por los cardenales bajo la presidencia del Sumo Pontífice-procedía a la elección del obispo. De esta manera, el Papa otorgaba la investidura canónica al presentado y emitía una bula de confirmación. El electo debía abonar todas las tasas correspondientes a la emisión de bulas a través de su agente en Roma, para que su designación tuviera efecto mediante la emisión de las cartas ejecutoriales (Barrio Gozalo, 2017a:24). 
Las reformas administrativas llevadas adelante por Felipe $\mathrm{V}$ en la segunda década de su reinado afectaron el proceso de la provisión cargos episcopales, incrementado la capacidad de la vía reservada, que privilegiaba el despacho a boca. De este modo, se procuró la disminución del número de actores involucrados en el proceso de selección de candidatos. Con la creación de las Secretarías de Despacho se menguó el poder de los Consejos, especialmente la facultad de participar en los nombramientos episcopales, que quedó a cargo de la Secretaría de Gracia y Justicia, fundada en 1714 (Alcaraz Gómez, 1996: 13). Las reformas se pudieron llevar adelante no solo gracias a los impulsos del equipo de gobierno del rey o a los precedentes del reinado de Carlos II, también por el hecho de que Felipe V fue la parte agraviada por el juego de lealtades de los funcionarios durante la Guerra de Sucesión, por lo que pudo imponer los cambios que consideró necesarios, lo que los funcionarios tuvieron que aceptar con docilidad para no perder la gracia real (Burgos Lejonagoitia, 2014: 81).

El proceso de provisión de obispados requería la concurrencia de Roma para su concreción. Las relaciones entre la Santa Sede y Felipe V fueron difíciles durante todo su reinado, alternando periodos de tensas relaciones y momentos de ruptura. En el año 1700, tras la muerte de Inocencio XIII (1691-1700), el cónclave eligió al cardenal Giovanni Francesco Albani quien tomó el nombre de Clemente XI (1700-1721). El grupo de cardenales que lo habría apoyado eran los zelanti, una corriente que había surgido a mediados del siglo XVII en la curia romana que abogaba por una mayor independencia diplomática de la Santa
Sede con respecto a las potencias europeas y que propugnaba por la recuperación de la centralidad pontificia en las relaciones internacionales y pretendía contrarrestar la secularización que estas padecían desde la Paz de Westfalia (1648). La Guerra de Sucesión Española se presentó para Clemente XI como una oportunidad de llevar adelante el proyecto de restablecer el rol de mediador del Papado en la política europea (Jedin, 1978: 214-220; Martín Marcos, 2011:33)

Si bien, Clemente XI había reconocido desde un principio a Felipe de Anjou como heredero legítimo de Carlos II, en el año 1709, tras las presiones ejercidas por el Archiduque Carlos en los territorios pontificios, el papa reconoció al pretendiente austriaco como rey de España. Inmediatamente, Felipe $\mathrm{V}$ ordenó el cierre de la nunciatura en Madrid y el retiro de sus embajadores en la corte romana. La ruptura entre ambas cortes (1709-1713) desnudó la mutua dependencia política, económica y administrativa.

En primer lugar, desde un punto de vista de la política europea, el problema era reconocimiento pontificio sobre Nápoles, cuyo soberano feudal era el papado, y que durante los siglos XVI y XVII había constituido una parte de la Monarquía Hispánica; en segundo lugar, el clero enfrentó el problema de la doble potestad, es decir si obedecían a Roma o al Corona, esta última se impuso; tercero, la ruptura generó inconvenientes en el funcionamiento administrativo cotidiano de la Iglesia, al verse afectada la normal provisión de cargos episcopales, lo que devino en numerosas sedes vacantes; en cuarto término, en materia espiritual, no solo negó a las diócesis vacantes la 
posibilidad de contar con sus prelados-pastores, sino que también imposibilitó a la feligresía conseguir numerosas dispensas, como por ejemplo, las matrimoniales. Por último, desde un plano económico, se interrumpió el flujo de dinero que ligaban a las cortes de Madrid y Roma, puesto que privaba al rey de aquellas contribuciones extraordinarias que requería a la iglesia española - es decir, las tres gracias: cruzada, subsidio y excusado - y, a su vez, la curia romana no podía percibir los ingresos correspondientes por las emisiones de bulas y otros trámites por preces (Barrio Gozalo, 2011: 212; Barrio Gozalo, 2017b; Domínguez Ortíz, 1979: 74).

Las dificultades financieras que atravesó la Monarquía trataron de sanearse por diferentes medios, tales como el incremento en la venta de plazas, las cargas impositivas y los donativos forzosos. El alto clero en general, y los obispos en particular, podían participar de la política real colaborando para que en sus diócesis no se compliquen las demandas de exacciones a las arcas de la Iglesia que se solicitaban desde Madrid (Aguirre Salvador, 2012: 258). Asimismo, podían contribuir al alivio de la Real Hacienda, evitando, en la medida de lo posible, solicitar dineros a la Corona, sobre todo, en las diócesis cuyas rentas eran más estrechas.

A partir de la ruptura con Roma, la Corona procuró incrementar su poder y el de los obispos. En un primer momento, ante la negativa pontificia de preconizar a los candidatos propuestos por Felipe V para las sedes vacantes, la Junta reservada del año 1712 elevó al rey su sugerencia que consistía en retornar a la tradición antigua, cuando los obispos se elegían, se aprobaban y se consagraban en España (Barrio Gozalo, 2017a: 25). Ya con el panorama claro del desenlace de la Guerra de Sucesión Española, en 1713, se habían restablecido las relaciones mediante el intercambio de emisarios, lo que no significó, aún, una solución al conflicto. En París se llevaron adelante las conversaciones entre el representante español y el cardenal Pompeo Aldrovandi, representante papal, donde el primero presentó los puntos de negociación, a saber, la reforma de la nunciatura, la dataría y el reconocimiento del archiduque (Barrio Gozalo, 2017b: 39). Roma mostró reparos y ralentizó el proceso, que condujo a un nuevo estancamiento del restablecimiento de las relaciones desde 1714 - no obstante, se logró normalizar la provisión de los obispados con la correspondiente colación pontificia-hasta que finalmente, en 1717 se firmó un precario concordato entre la Santa Sede y Felipe V que dio resolución al problema.

A raíz de la política italiana de Alberoni, en el año 1718 las relaciones se volvieron a quebrar. Para 1719, el cardenal Claudio Aquaviva, embajador de España en Roma, sugería a Alberoni devolver a los prelados sus facultades originales o primitivas en materia de provisión de beneficios en sus diócesis y su la capacidad de dispensar a los fieles (Barrio Gozalo, 2017a: 25; Barrio Gozalo, 2017b: 50). Si bien no tuvo el visto bueno del rey, el objetivo de Alberoni era presionar al pontífice para obtener la mitra sevillana. Pero la propuesta de Aquaviva, no solo debe ser considerada como una estrategia de presión a la corte romana, sino como el reflejo de una queja constante del clero español y la Corona por los abusos de la curia, especialmente por los excesivos derechos que cobraba la Dataría, y por 
los arbitrariedades cometidas por la curia en la provisión de beneficios durante los meses apostólicos, que por lo general recaía en sujetos que no reunían las calidades y méritos necesarias, y que lesionaban la moral del clero.

Las relaciones se reestablecieron nuevamente en el año 1720, tras la caída en desgracia de Alberoni. A partir de entonces, la Corona orientó sus esfuerzos hacia dos objetivos: reformar el clero-limitando los abusos y eliminando los vicios morales que padecía - y obtener el patronato regio universal sobre toda la iglesia española. En este último punto, la demanda regia fue posible ya que había cambiado la percepción en torno a las concesiones pontificias. El regalismo del siglo XVIII partía de la convicción de que todos aquellos aspectos eclesiásticos que no fueran espirituales o dogmáticos eran competencias del poder del rey, y que las regalías - es decir, los privilegios que concede el pontífice a los monarcas en materia de gobierno y administración de las iglesias - eran derechos inherentes al rey, y no una donación gratuita de los papas, tal como eran entendidas en el siglo XVII (Morgado García, 2000: 192; Egido, 1979: 123-249).

Felipe V pretendía tener un control no solo en la provisión de obispados, sino en todo el sistema beneficial. La Monarquía ya contaba con dicho privilegio cuando los Reyes Católicos obtuvieron en 1486 el patronato regio sobre el Reino de Granada, luego, sobre las islas Canarias, y en 1508 para los territorios indianos. El patronato indiano, afectó a toda la estructura jerárquica y se asentó sobre cuatro pilares: el derecho de presentación, el pase regio, el recurso de fuerza y la administración de los bienes eclesiásticos. Pero el patronato que había obtenido Carlos I en 1523 para la iglesia castellana y aragonesa era más acotado que el indiano. Si bien podía crear en sus territorios ibéricos un episcopado adicto, no podía controlar otros resortes del poder eclesiástico, como los cabildos catedralicios, ya que los obispos no podían nombrar durante los meses apostólicos a ningún prebendado. Las dignidades y canonjías del clero capitular, por lo general, estaban en manos de las principales familias patricias locales. Esto representaba una verdadera limitación al poder de los prelados, ya que no podía premiar a quienes lo ayudaban en su tarea ministerial (Dellaferrera, 1999: 387; Morgado García, 2000: 35; Iglesias Ortega, 2011: 392; Barrio Gozalo, 2017b: 24)

El fallecimiento de ClementeXI en 1721 permitió un diálogo más fluido entre Madrid y Roma, al desaparecer los zelanti. El entendimiento alcanzado no estuvo exento de roces, al menos durante los pontificados de Inocencio XIII (1721-1724) y Benedicto XIII (1724-1730). Ya con Clemente XII (1730-1740), la tensión por la consecución del patronato universal devino en una nueva ruptura en el año 1736. Un año antes, se había creado la Junta del Real Patronato, encabezada por el obispo de Málaga y presidente del Consejo de Castilla, Gaspar de Molina, quien a partir de la pesquisa realizada por el abad de Vivanco pretendía reclamar una serie de beneficios eclesiásticos que a su entender habían sido usurpadas por el Papado al patronato regio. Una serie de sucesos violentos en la Ciudad Eterna contra los oficiales del rey a causa de la actuación de las tropas españolas en la península italiana precipitó el cierre de la embajada 
en Roma y la nunciatura en Madrid, lo que retrasó nuevamente las provisiones episcopales para las sedes vacantes. Por entonces Molina entendió que era el momento de radicalizar su postura y aprovechó para exigir entre sus demandas el reconocimiento pontificio de Carlos de Borbón, hijo de Felipe V e Isabel de Farnesio, como rey de Nápoles y Sicilia, y avanzar hacia la obtención del patronato universal. En 1737, tras la calma en los ánimos de ambas partes y el restablecimiento de las relaciones diplomáticas, se iniciaron las negociaciones que culminaron en la suscripción del concordato ese mismo año, cuya precariedad quedó patente en el artículo 23 que prometía tratar el asunto en un futuro próximo, sin embargo, dejaba sin resolver en lo inmediato el patronato regio. La habilidad del nuncio Valenti permitió a Clemente XII dilatar las negociaciones hasta su muerte en 1740. El papa Benedicto XIV (1740-1758) no concedió el patronato regio universal a Felipe V, sino a su hijo Fernando VI (1746-1759) a través del Concordato de 1753 (Díaz Molina, 1999: 194; Sigüenza Tarí, 1997; Barrio Gozalo, 2017b:59-68)

En síntesis, a lo largo del reinado de Felipe V, la provisión de obispado se convirtió en un asunto de capital en el marco de las tensas relaciones que tuvo con Roma. Tras ser preconizados por el Papa, los prelados realizaban un juramento de fidelidad y obediencia al pontífice, cláusula que colisionaba con las pretensiones del rey de sujetar a su clero. No obstante, el episcopado en general tomó partido por la política de la Corona y sirvieron como agentes reales a lo largo y ancho de la monarquía, pues el título que los obispo ostentaban del "consejo de su majestad" no era solo honorífico, sino que los facultaba a tomar activa intervención en la gestión de gobierno, al informar a los consejos sobre los problemas en la administración de sus jurisdicciones y elevar propuestas de soluciones (Mazín, 2012:380).

\section{La trayectoria de tres obispos}

Los casos seleccionados son, primero, Lorenzo Armegual de la Mota (obispo de Cádiz), refleja una experiencia circunscripta sólo al ámbito peninsular; segundo - el cuzqueño Juan de Sarricolea y Olea - revela el desarrollo de un caso propiamente indiano; y tercero, José Antonio Gutiérrez de Zevallos, muestra el desenvolvimiento de una trayectoria compartida en España e Indias. Esta plataforma permite cotejar y distinguir aquellos elementos que fueron singulares y generales en cada una de las trayectorias de sujetos que lograron el nombramiento para una mitra. El objetivo es demostrar a través del análisis de estos agentes espirituales el carácter integrado de la Monarquía Española a través de sus carreras, su circulación dentro del conjunto territorial común y su promoción a los cargos episcopales.

Actualmente, los trabajos comparativos relativos a la Monarquía Española gozan de un notable impulso. Un ejemplo de ellos son las investigaciones sobre las dinámicas de la nobleza titulada (Felices de la Fuente, 2012), los estudios sobre familias en Córdoba del Tucumán y Murcia emprendidos por los equipos de investigación de Mónica Ghirardi y Antonio Irigoyen López (Ghirardi, 2016), y sobre el clero regular en el Río de la Plata y Brasil (Ayrolo, 2015). 
Peter Burke señala la importancia del método comparativo como estrategia para vincular teoría e historia, especialmente, para advertir aquellos rasgos de la que están ocultos y que solo son perceptibles a través del contraste entre diferentes realidades sociales (Burke, 1996: 37). La comparación y el estudio de caso permiten un control conjunto de las generalizaciones y la posibilidad de refutarlas (Sartori, 1999: 46). Más aún, si se aborda desde la óptica del sistema cortesano, donde adquiere énfasis las relaciones personales. En efecto, la comparación desde una amplia perspectiva permite cotejar y establecer con mayor precisión los alcances y límites de las facciones presentes en el reino (González Cuerva, 2017: 3). Entiendo por facción a una coalición que se agrupa "por, o en nombre de, una persona" y que se define por la existencia de una rivalidad y una competencia por el honor y el acceso a los recursos (Boissevain, 2012: 168). Hoy, la historiografía apela al concepto de redes sociales para el análisis de estos vínculos, precisamente, por carácter dinámico mismo que presentan las relaciones humanas. Las redes se presentan como flexibles y versátiles a lo largo del tiempo, y al historiador le permite constituir dichos grupos en función de un problema dado para su explicación (Ponce Leiva y Amadori, 2008: 26).

\subsection{Lorenzo Armengual de la Mota}

Lorenzo Armengual de la Mota nació en Málaga el 23 de octubre de 1663. Morgado García postula que este obispo era de orígenes humildes sin embargo investigaciones recientes sostienen que provenía de una familia hidalga cuyos ascendientes habían ocupado cargos en la ciudad de Antequera. Sus padres fueron don José Armengual, que se desempeñó como alcalde ordinario de Antequera, y doña Teresa Álvarez del Pino, hija de un rico comerciante. Desde niño, Lorenzo Armengual asistía con su padre al convento dominico de la ciudad, situación que les permitió conocer al clérigo Antonio Ibáñez de la Riva y Herrera, canónigo magistral del cabildo eclesiástico local, quien se hizo cargo de la educación del joven Lorenzo Armengual que estudió Gramática en la Escuela del Cabildo Catedralicio de Málaga (Lara Villodres, 2007: 31).

Antonio Ibáñez de la Riva Herra, el mentor de Lorenzo Armengual, era descendiente de un prominente linaje de Cantabria, los marqueses de Villa Torre. Fue becado en el Colegio de San Ildefonso en Alcalá de Henares. Había iniciado su carrera eclesiástica como cura en Gajano e inmediatamente había ascendido a la canonjía ya mencionada en Málaga. En 1680 Ibáñez había sido creado obispo de Ceuta y fue consagrado como tal en 1685. Allí llevó consigo a Armengual como su secretario. Carlos II propuso a Ibáñez en 1687 para el arzobispado de Zaragoza, lo que significó no solo un gran salto en su cursus honorum, sino también para el de su pupilo. En efecto, Armengual fue nombrado comisario del Tribunal de la Inquisición en Aragón y notario del Santo Oficio en Sevilla. Además, Ibañéz lo consagró como obispo de Gironda en 1701, un título honorífico, puesto que su mentor lo necesitaba como visitador y auxiliar de la arquidiócesis (González, 2001: 145; Lara Villodres, 2007: 59)

En 1690, Armengual había solicitado ingresar como capellán de honor de Carlos II, realizando 
las correspondientes demostraciones de limpieza de sangre y daba cuenta de su suficiencia pecuniaria, declarando que gozaba de dos beneficios simples en la parroquia de San Juan Bautista de Villa Marchena y en San Juan Bautista de Écija, y cuatro capellanías en Málaga (Archivo General de Palacio, Personal, Caja 7812, expediente 4). Ese mismo año, Ibáñez había sido nombrado por el rey presidente del Consejo de Castilla, lugar privilegiado que le permitió remitir buenas referencias de su protegido al monarca (Lara Villodres, 2001: 61). Mientras tanto, por aquellos años, Armengual obtuvo el título de doctor en Cánones por la universidad de Zaragoza, puesto que consideraba necesario reforzar con sus méritos las recomendaciones que brindaba su mentor en los altos círculos cortesanos.

Durante la Guerra de Sucesión fue clave la inclinación de Ibáñez hacia el bando borbónico, lo que le valió en 1703 que Felipe V lo nombrase virrey y capitán general de Aragón. En 1705 los ejércitos del archiduque habían tomado Barcelona y se preparaban para penetrar en Cataluña y José de Grimaldo encargó el aprovisionamiento al arzobispo, quien solicitó la ayuda de Armengual para dicha tarea. Fue convocado a Madrid donde empezó a trabajar junto con Jean Orry, siendo nombrado desde entonces gobernador de Hacienda (Castro, 2004: 136). Armengual logró insertarse en el equipo francés de gobierno como un colaborador próximo a Orry gracias a quien pudo insertarse en los cuadros de gobierno en la corte, y continuar con un trayecto exitoso, independiente de su valedor Ibáñez, que murió 1710 en el ejercicio del cargo de inquisidor general. Tras el desdoblamiento de las dos Secretarías del
Despacho Universal realizado en 1714, el manejo de los asuntos económicos quedó a cargo de la Veeduría General, bajo la supervisión de Orry, quien, además, participaba personalmente en otros negocios del reino (Burgos Lejonagoitia, 2014: 88). Por esta razón, Felipe V decidió crear la Intendencia Universal de Hacienda que recayó en Lorenzo Armengual quien representaba a Orry, gozando por lo tanto de un acceso privilegiado al rey (Sallés Vilaseca, 2018: 29)

Sin embargo, tras la muerte de la primera esposa de Felipe V, María Luisa Gabriela de Saboya en 1714, y el segundo matrimonio con Isabel de Farnesio, significó la caída del equipo francés y su sustitución por la llegada de los italianos al poder, como Giulio Alberoni. Primero, fue despedida la princesa de los Ursinos, en diciembre de 1714, y tras ella, la caída progresiva a lo largo de 1715 de Jean Orry, Melchor de Macanaz y el confesor real Pierre Robinet (Kamen, 2010: 125).

Antes de la anunciada caída de Ursinos, Robinet, aún en el confesionario regio consigue obtener una mitra de para asegurar a Armengual:

visto la Consulta del Consejo en Govierno en que propone Personas para el Obispado de Cádiz que está vaco por muerte de Don Fr. Alonso de Talavera, y su valor cada año es de cerca de diez mil Ducados. Y atendiendo a las buenas prendas de el Obispo de Gironda, propuesto en primer lugar en razón de prudencia, zelo y aplicación a lo que respe[c]ta al Real servicio, bien notorio a V.M. en los empleos que ha tenido a su cargo, tanto en lo político como en el govierno episcopal en 
que sirvió largo tiempo al último Arzobispo de Zaragoza. Juzgo que V.M. puede servirse de presentarle para esta Mitra (Alcaráz Gómez, 1996: 28).

El rey respondió afirmativamente y elevó a clemente Clemente XII la presentación quien dio su aprobación apostólica en 1716. Al año siguiente, Armengual tomó posesión efectiva. En el momento de su designación Madrid y Roma estaban en proceso de apertura de negociaciones del Concordato de 1717. Por ello la provisión episcopal para Cádiz pudo ser ejecutada con rapidez.

Claramente, Armengual cayó en desgracia junto al equipo al que pertenecía. No obstante, de acuerdo con la documentación encontrada en la Biblioteca Nacional de España, se puede corroborar que Lorenzo Armengual pudo mantener un diálogo fluido con el rey. Tal como lo demuestra un problema que tuvo el obispo en el año 1725, en el ejercicio del "Vicario General de la Armada" en el pleito con los militares respecto de comer carnes y lacticinios en los días de precepto, que pudo ser solucionado gracias a la intervención regia (BNE, mss. 12950/24). Asimismo, se puede verificar el interés del prelado en tener noticias de los sucesos europeos, a través de la correspondencia que sostenía con sus contactos que había conseguido cuando estaba de servicio en la corte (BNE, mss. 12948/6). Lorenzo Armengual terminó sus días como prelado de la sede gaditana en 1730 .

\subsection{Juan de Sarricolea y Olea}

Juan Manuel de Sarricolea y Olea nació en Huánuco el 7 de diciembre de 1670. A través de la crónica
Anales del Cuzco, sabemos que sus padres fueron don Diego Ordoño de Sarricolea y Zamudio y doña María de Olea. Gracias a su hermano, Martín de Sarricolea y Olea, Juan de Sarricolea logró la protección de quien fue virrey del Perú en dos oportunidades fray Diego Morcillo Rubio Auñón, un hombre que representaba los intereses del sector minero que elevaba numerosos donativos al rey, atención que el monarca retribuía complaciendo sus sugerencias para las provisiones de cargos. Cuando Morcillo se desempeñó como obispo de La Paz y de Charcas, designó a Martín de Sarricolea como su provisor y vicario general, un cargo por lo general reservado a las personas confidentes de los prelados. Martín de Sarricolea también se desempeñó también como canónigo magistral en Charcas y había sido nombrado obispo coadjuntor del Paraguay por recomendación de su valedor, pero no llegó a ejercer el cargo por haber fallecido en 1720 (Archivo y Biblioteca del Arzobispado de Sucre, Actas Capitulares, vol. 15, caja 7; Pastells, 1946:183).

En cuanto a la formación de Juan de Sarricolea, hay que mencionar que fue colegial de San Martín en Lima, que había sido fundado por la Compañía de Jesús en 1582 y que se había constituido en uno de los más prestigiosos del virreinato, allí acudían los hijos de las familias más notables del Perú (Burrieza Sánchez, 2010: 205). La importancia del ejercicio educativo por parte de la Compañía radicaba en la preocupación por el control ideológico y su capacidad para inmiscuirse dentro de las redes y clientelas locales. Este vínculo primario que establece Sarricolea con los miembros de la orden ignaciana sería de capital importancia a lo largo de su carrera. 
Posteriormente, se doctoró en Teología en la Universidad de San Marcos de Lima. Inició su trayectoria como clérigo siendo pastor de indios durante veinte años consecutivos en el cuarto y doctrina de Maray, en el Arzobispado de Lima, y recibió el cargo de vicario y juez eclesiástico de ella y de las provincias de Chancay y Cajatambo. Mientras fue párroco y rector de la vice parroquia de San Lázaro en Lima, también se desempeñó como catedrático de vísperas de Teología en la Universidad de San Marcos. En 1719, Juan de Sarricolea se había presentado a la oposición para una canonjía penitenciaria en la catedral de Lima, la cual obtuvo gracias a la intervención del provincial de la Compañía de Jesús, el padre Antonio Garriga, debido a que la oposición había tenido vicios de forma y por la no intervención del virrey Morcillo, quien había recibido peticiones de otros oponentes para que tomase cartas en el asunto (Archivo General de Indias, Indiferente General, $N^{\circ} 46$; Barbero, 1995: 129).

Cayetano Bruno apunta que la recomendación donde aparece nombrado Sarricolea para ocupar la mitra tucumana está fechada en 4 de septiembre y es efectuada por el confesor real, que por entones era Gabriel Bermúdez vinculado al partido español de la corte y al rey Luis I (1724) (Bruno, 1966:44). Juan de Sarricolea fue sugerido por el confesor del Rey, quien en virtud del Real Patronato Indiano presentó la candidatura ante Roma, donde el papa InocencioXIII en el Consistorio Secreto del 22 de noviembre de 1723 dispuso el traslado del entonces obispo del Tucumán Alonso del Pozo y Silva para la diócesis de Santiago de Chile y la promoción de Juan de Sarricolea y Olea para la mitra tucumana (Astrada, 1998: 176).
Fue consagrado por el arzobispo de Lima Diego Morcillo Rubio de Auñón en octubre de 1724 y tomó posesión de su diócesis en enero de 1725 a través de su Provisor y Vicario General Francisco Bazán de Pedraza. Juan de Sarricolea inició su ministerio con la realización de la visita a la diócesis en abril de 1726 (Bruno, 1966: 424-425). Si bien la diócesis presentaba numerosos problemas de relajamiento disciplinar, en aspectos que eran comunes en Indias, como la falta de registro de los bienes de instituciones sujetas a la jurisdicción episcopal, como los conventos de San José y de Santa Catalina de Córdoba, y problemas como el amancebamiento de los curas, entre otras, propició a que el obispo llevase adelante una serie de reformas, pero aplicadas con cierto grado de moderación y sin las pretensiones de subsanarlas totalmente, puesto que un enfrentamiento con las élites locales podía significar un truncamiento en su carrera eclesiástica.

La labor del obispo se vio premiada con la presentación que hizo el rey a Clemente XII, y confirmada en el Consistorio Secreto del 24 de julio de 1730, cuando se promovió al obispo a la mitra de Santiago, vacante por el ascenso del obispo Alonso del Pozo y Silva al Arzobispado de Charcas (Astrada, 1998: 178). En diciembre de 1731, partió desde la ciudad de Córdoba en dirección a Santiago de Chile. Tres años después, en 1734, hubo de ser presentado para la mitra vacante de Cuzco por la muerte del obispo carmelita fray Bernardo Serrada en marzo de 1733. Sarricolea tomó posesión del obispado en julio de 1734 . El domingo 2 de octubre de 1740 había fallecido el obispo cuzqueño Juan de Sarricolea y Olea a los 69 años. Sus restos han sido enterrados el $10 \mathrm{de}$ 
octubre en la iglesia de la Compañía de Jesús en cumplimiento de su voluntad expresada mientras estuvo en Córdoba (Anales del Cuzco, 304; Sierra, 1957: 153).

\subsection{José Antonio Gutiérrez de Zevallos}

La trayectoria del obispo José Antonio Gutiérrez de Zevallos resulta un caso interesante porque inició su cursus honorum como fiscal de la Inquisición en Cartagena de Indias (1713-1718) pasando pronto a Lima como inquisidor del Santo Oficio (1718-1730) donde por sus enlaces políticos casi se entorpece su carrera. No obstante, gracias a los vínculos que pudo estrechar logró sortear las adversidades y ser promovido a la mitra tucumana en 1730 que ejercería efectivamente desde 1733 hasta 1740, cuando fue elevado como arzobispo de la Ciudad de los Reyes (1742-1745). Tal como señala Rodolfo Aguirre Salvador, el éxito de una carrera eclesiástica se nutría, y dependía en gran medida, tanto de los méritos personales como de sus relaciones clientelares con autoridades o individuos poderosos (Aguirre Salvador, 2000: 79).

Zevallos nació en Puente Viesgo, en Cantabria, sus padres fueron Juan Gutiérrez de Zevallos el Caballero y María de Quijano y Vargas (Archivo Histórico Nacional, Inquisición, 1281, expediente 11). Durante su juventud había sido becado en el Colegio de la Orden de Santiago, más conocido como Colegio del Rey; allí permaneció entre los años 1701 y 1709 (Archivo de la Universidad de Salamanca - en adelante, AUSA -, Libros de Matrícula, 414, f. 17 r.; AUSA, 415, f. 17 v., AUSA, 416, f. 18v., AUSA, 417, f. 19 v.). Se licenció y doctoró en Cánones en la Universidad de Salamanca y fue caballero del hábito de la orden de Santiago (Mendiburu, 1876: 359). Su carrera eclesiástica había iniciado en 1710 , cuando había sido designado por el inquisidor general Antonio Ibáñez de la Riva Herrera como inquisidor fiscal Cartagena de Indias, plaza que pudo cubrir en el año 1713. Posteriormente fue trasladado a Lima en 1718, donde se desempeñó como inquisidor hasta 1730 , al anoticiarse de su ascenso a la mitra tucumana.

A su llegada a Lima se desempeñaba como arzobispo Antonio de Soloaga (1714-1722), quien pretendía corregir los vicios del clero peruano. Para ello contó con el apoyo del clérigo romano José María Barberí, que pertenecía al séquito de Cármine Nicolás Caraccioli, Príncipe de Santo Buono, y virrey del Perú entre 1716 y 1720. En el lado opuesto se encontraba el arzobispo de Charcas Diego Morcillo Rubio Auñón que había ejercido anteriormente el cargo de virrey de manera interina. Tras él se encontraba una poderosa facción compuesta por el inquisidor Ibáñez de Segovia, la red familiar y clientelar del oidor decano de Lima, Miguel Nuñez de Sanabria, la mayoría de los obispos del Perú y los mineros del Potosí. Esta red actuó para que cayese Santo Buono e instalar a Morcillo nuevamente como virrey interino hasta 1724. El arzobispo-virrey, tras la muerte de Soloaga (1724) lanzó una persecución contra los colaboradores del difunto metropolitano y del exvirrey. Atacó directamente a Barberí, a quien se lo acusó saltarse la vía regia al escribir una Relación dirigida directamente al Papa en la denunciaba las corrupciones del clero peruano. Otra víctima fue el inquisidor Gutiérrez de Zevallos: 
Uno de los mantenedores de la sacrificada y hasta arriesgada amistad y recuerdo hacia quien fuera su mentor [el príncipe de Santo Buono] fue el inquisidor segundo del tribunal de Lima, «el grande amigo» José Antonio Gutiérrez de Ceballos, quién se mantuvo en el cargo entre 1718 y 1730, y que pareciera haber esperado de la influencia del recién sustituido virrey napolitano su promoción a mejores destinos (Moreno Cebrian, 2003: 268).

Por entonces, se esperaba que Santo Buono fuese designado presidente del Consejo de Indias, sin embargo, fue elegido Andrés de Pez. Esta elección y la persecución del virrey-arzobispo Moricillo significaban para Zevallos una caída en desgracia.

Su situación mejoró en 1724 a la llegada del nuevo virrey Don José de Armendáriz y Perurena, Marques de Castelfuerte, quien armó su círculo político a partir de los seguidores de Santo Buono. El nuevo virrey creó una sólida red clientelar tanto en la Península como en Lima y fue quien sugirió a Gutiérrez de Zevallos para ocupar alguna mitra, a razón de sus cualidades: rectitud moraly firmeza para imponer orden y disciplina. Por estos años, la elección de los obispos estaba en sintonía con la política de la Corona de reformar la Iglesia Española, plasmada en la bula de Inocencio XIII, Apostolici Ministerii de 1723.

El Consejo de Indias había sugerido al rey en 1729 que el inquisidor Zevallos sea elevado como obispo a la diócesis de Concepción, ocupada por Francisco Antonio de Escandón. A este prelado estaba previsto transferirlo a la sede vacante del
Tucumán, sin embargo, este no aceptó, razón por la cual hubo de intervenir el confesor real para que Zevallos ocupase la vacante del Tucumán por el traslado de su obispo Juan de Sarricolea y Olea a la sede de Santiago de Chile (Bruno, 1966: 439).

En definitiva, la elección de José Antonio Gutiérrez de Zevallos como obispo fue realizada "a boca" por Felipe V y el confesor real William Clarke el 21 de febrero de 1730 y en marzo del mismo año se emitió desde Sevilla la real cedula de gobierno de la diócesis para el nominado. Cabe recordar, que el confesor Clarke sustituyó a Bermúdez en 1726, y su posición era próxima a la reina, pero, además, era sospechoso de estar “próximo y partidario de la casa imperial en Viena" (Contreras, 2004: 491). El candidato Gutiérrez de Zevallos fue presentado al papa a través de la real cédula fechada en Cazalla el 26 julio de 1730. En el proceso consistorial oficiaron de testigos los procuradores de la Compañía de Jesús en el Perú, el padre Juan Francisco de Castañeda y Felipe del Castillo, "que gozó [...] de la total confianza de Castelfuerte, hasta el punto de confiarle la conducción de parte de su fortuna" (Moreno Cebrian y Sala i Vila, 2004: 195). Clemente XII confirmó la elección en el consistorio secreto de febrero de 1731.A razón de la distancia entre las sedes episcopales indianas, le permitieron que sea consagrado por un obispo y dos dignidades. Finalmente, el rey envió las ejecutoriales desde Sevilla en mayo de 1731.

Mientras tanto, la designación del Zevallos coincidía con el restablecimiento de las tensiones en las relaciones entre la Santa Sede y el rey, desatadas tras la firma del Tratado de Sevilla de 1729, en virtud del cual las potencias reconocían los 
derechos del príncipe don Carlos a la sucesión de los ducados de Parma y Plasencia, sin la investidura feudal pontificia lo que fue tomado por Clemente XII como un agravio (Vidal, 2001: 202). En este marco, Gutiérrez de Zevallos había recibido en septiembre de 1730 la real cedula de gobierno de la diócesis, pero prefirió esperar a recibir las bulas pontificias, que llegaron en mayo de 1732 . Su consagración:

La realizó, el 6 de julio de aquel año (1732), en la metropolitana de los Reyes, el arzobispo don Francisco Antonio de Escandón, con la asistencia, a falta de otros dos obispos, del deán don Felipe Manrique de Lara y del arcediano doctor Andrés de Munive, en presencia del virrey marqués de Castelfuerte, la Real Audiencia, el Cabildo y los demás tribunales de la ciudad capital del virreinato (Bruno, 1966: 440).

A fines de ese año emprendió su travesía con destino a la ciudad de Córdoba. Zarpó del Callao y llegó a Valparaíso en diciembre de 1732. Allí permaneció en Santiago con su predecesor Sarricolea hasta marzo de 1733. Su labor en el obispado del Tucumán se caracterizó por su férrea voluntad de corregir los vicios del clero local (Chiliguay, 2017: 195-218). Por su gestión en la diócesis consiguió ser promovido como arzobispo de Lima en 1740 , donde falleció el 16 de enero de 1745.

\section{Conclusión}

Uno de los legados de la Guerra de Sucesión fue la tensa relación entre España y la Santa Sede que osciló entre periodos de negociaciones y periodos de clausura total del diálogo, pero otro también fue la completa evaporación del contenido de la "Monarquía Católica" lo que la puso en una paridad con Roma de manera tal que ambas partes se sentarían a negociar y solucionar el problema a través de un Concordato. Este elemento era imposible de llevarse a cabo durante el siglo XVII porque se consideraba que la razón de ser de la monarquía se debía supeditar a la jurisdicción e influjo de la Iglesia (Martínez Millán, 2013). El pontificado de Clemente XI significó el fin del proyecto celante de recuperar el rol de mediador del papado ante cualquier conflicto, pues era vulnerable a ceder ante la presión que cualquiera de los contendientes.

La ruptura de relaciones entre Madrid y Roma sacó a la luz la mutua dependencia entre ambas cortes en diversas materias. Particularmente, resultaron afectadas las provisiones episcopales, generando largos años de sede vacante, situación que tendió a normalizarse parcialmente a partir de 1713, aunque los roces entre ambas partes continuaban. La política de Felipe $V$ desde entonces tendió hacia una examinación más exhaustiva de los candidatos a las prebendas, tanto en sus méritos como en su grado de adhesión a las políticas de la Corona, encaminada desde la década de 1720 hacia la consecución del Patronato Regio Universal y la corrección de los vicios del clero. Estos elementos fueron comunes en los obispos Armengual, Sarricolea y Gutiérrez de Zevallos, quienes si bien tenían potentes valedores - Jean Orry, fray Diego Morcillo y el virrey Castelfuerte, respectivamente - también hay que destacar que los tres tuvieron una destacada formación 
universitaria y al momento de su designación contaban con un abultado cursus honorum.

La Guerra de Sucesión representó una oportunidad para los hidalgos que pudieron acceder a diferentes cargos de jerarquía en el servicio real, en detrimento de los grandes nobles. En esta óptica hay que analizar la carrera de Lorenzo Armengual, quien, gracias a la postura que adoptó su mentor hacia el servicio al bando borbónico - definición de suma importancia en la España peninsular - le permitió a Armengual acceder a los cargos cortesanos y posteriormente integrarse al equipo francés de gobierno, obteniendo la protección de Jean Orry. Mientras tanto, Indias no representó un problema en cuanto a la fidelidad al monarca Borbón, pero la coyuntura bélica y las necesidades de la Real Hacienda, permitieron a las élites indianas obtener mitras, no mediante la venalidad directa - puesto que eso sería simonía -, pero sí a través de las sugerencias que desde América partían a la Cámara de Indias, que se veían reforzadas por las sugestivas cartas que algunos personajes como el virrey del Perú, fray Diego Morcillo, elevaban al rey, recordando los generosos donativos enviados, en vistas de que el monarca atendiera a las peticiones indianas. En este sentido, resulta interesante la relación entre los méritos de Juan de Sarricolea y el contacto brindado por su hermano Martín de Sarricolea, hombre de confianza de fray Diego Morcillo. A diferencia de los dos casos anteriores, la trayectoria de Gutiérrez de Zevallos que se inserta en un mundo a ambos lados del Atlántico. Si bien, era miembro de una familia linajuda y pertenecía a la alta nobleza, tuvo que adoptar una postura más flexible en cuanto a sus mentores. Aparentemente, gozó de la protección también de Ibáñez de la Riva quien como inquisidor general lo designó para la plaza de fiscal del Santo Oficio en Cartagena de Indias. En América, tuvo que adaptarse a las cambiantes circunstancias, puesto que el escenario estaba marcado por las disputas de poder en el virreinato entre dos facciones, el sector minero y el reformista, el primero encabezado por fray Diego Morcillo, y el segundo por los virreyes Santo Buono y Castelfuerte. La adscripción de Gutiérrez de Zevallos a este último grupo le permitió - una vez asentados en el poder en la segunda mitad de la década de 1720 - acceder a una mitra.

Finalmente, en el análisis de los cursus honorum se puede corroborar la movilidad de estas personas tanto en la España, en Indias y entre ambas, lo que demuestra el carácter integrado de la Monarquía.

\section{Referencias citadas}

Aguirre Salvador, R. (2000): "El ascenso de los clérigos de Nueva España durante el gobierno del Arzobispo José Lanciego y Eguilaz", Estudio de historia novohispana, 22, pp. 77-110.

Aguirre Salvador, R. (2012): Un clero en transición. Población clerical, cambio parroquial y política eclesiástica en el arzobispado de México, 1700-1749, México, Iberoamericana Vervuert.

Alcaraz Gómez, J. (1996): “Documentos. Felipe Vy sus confesores jesuitas. El "cursus" episcopal de algunos personajes ilustres del reinado", Revista de historia moderna, 15, pp. 13-46.

Anónimo (1901): Anales del Cuzco. 1600 a 1750, Lima, 
Imprenta del Estado.

Artola Renedo, A. (2013): De Madrid a Roma. La Fidelidad del episcopado en España (1760-1833), Gijón, Trea.

Astrada, E. y J. Consigli (1998): Actas consistoriales y otros documentos de los obispos de la diócesis del Tucumán (s. XVI al XIX), Córdoba, Prosopis Editora.

Ayrolo, V. (2015): "El lugar de los regulares. Reformas, restauración y nuevo orden en el mundo iberoamericano: Argentina y Brasil en clave comparada", Revista de História Comparada, 9 (1), pp. 119-144.

Barbero, S., E. Astrada, J. Consigli, (1995): Relaciones ad limina de los obispos de la Diócesis del Tucumán (s. XVII al XIX), Córdoba, Prosopis Editora.

Barrio Gozalo, M. (2011): "El cardenal Alberoni y España. Política religiosa y carrera eclesiástica", Hispania Sacra, 63 (127), pp. 205-234.

Barrio Gozalo, M. (2017a): “Los obispos españoles y el poder real en el siglo XVIII" en E. Callado Estela, ed., De Rebus Ecclesiae. Aspectos de historiografía eclesiástica sobre el siglo XVIII, Valencia, Institució Alfons el Magnànim-Diputación Valencia, pp. 21-39.

Barrio Gozalo, M. (2017b): La Embajada de España en Roma en la primera mitad del siglo XVIII, Madrid, Ministerio de Asuntos Exteriores y Cooperación.

Benito Aguado, M. T. (1994): "Clero e historia social; nuevas perspectivas de estudio”, en E. Martínez Ruiz y V. Suárez Grimón, eds., Iglesia y sociedad en el Antiguo Régimen, vol. I, Las Palmas de Gran Canaria, Universidad de Las Palmas de Gran Canaria, pp. 41-46.
Boissevain, J. (2012): “Coaliciones”, en F. Requena Santos, ed., Análisis de redes sociales: Orígenes, teorías y aplicaciones, Madrid, Centro de Investigaciones Sociológicas, pp. 147-183.

Bruno, C. (1966): Historia de la Iglesia en Argentina, T. IV, Buenos Aires, Don Bosco.

Burgos Lejonagoitia, G. (2014): Gobernar las Indias. Venalidad y méritos en la provisión de cargos americanos, 1701-1746, Almería, Editorial Universidad de Almería.

Burke, P. (1996): Venecia y Amsterdam. Estudio de las élites del siglo XVII, Barcelona, Gedisa.

Burrieza Sánchez, J. (2010): “La estrategia y ministerio educativo en la antigua Compañía de Jesús (siglos XVI-XVIII), en J. L. Betrán, ed., La Compañía de Jesús y su proyección mediática en el mundo hispánico durante la Edad Moderna, Madrid, Sílex, 2010, pp. 179-218.

Castro, C. (2004): A la sombra del Felipe V. José de Grimaldo, ministro responsable (1703-1726), Madrid, Marcial Pons.

Chiliguay, A. (2017): “Gobernar con celo la diócesis como servidor de dios y como fiel vasallo de su majestad: José Antonio Gutiérrez de Ceballos, obispo de Tucumán (1733-1740)", en VV. AA., La enseñanza de las Humanidades y las ciencias sociales a través del mundo digital, Madrid, Ediciones Digitales ED, pp. 195-218.

Comella Gutiérrez, B. (2008): “Los nombramientos episcopales para la Corona de Castilla bajo Felipe III, según el Archivo Histórico Nacional: una aproximación”, Hispania Sacra, 60 (122), pp. 703-733. 
Contreras, J. (2004): “Descargar la Conciencia Real: ¿confesor o ministerio?”, en A. Alvar, et al., eds., Política y cultura en la época moderna (Cambios dinásticos. Milenarismos, mesianismos y utopías), Alcalá, Universidad de Alcalá.

Dedieu, J. P. (2000): “La Nueva Planta en su contexto. Las reformas del aparato del Estado en el reinado de Felipe V", Manuscrits, 18, pp. 113-139.

Dedieu, J.P. (2005): “Amistad, familia, patria...y rey. Las bases de la vida política en la monarquía española de los siglos XVII y XVIII", Mélanges de la Casa de Velázquez, 35 (1), pp. 27-50.

Dellaferrera, N. (1999): "La Iglesia diocesana: las instituciones”, en VV.AA., Nueva historia de la Nación Argentina, T. II, Bs. As., Planeta, pp. 385-415.

Díaz Molina, F. (1999): "Fray Gaspar de Molina. Obispo de Málaga”, Isla de Arriarán, 13, pp. 189-199.

Domínguez Ortiz, A. (1979): "Regalismo y relaciones Iglesia-Estado en el sigloXVII”, en R. García Villoslada, dir., Historia de la Iglesia en España, tomo IV, Madrid, Biblioteca de Autores Cristianos, pp. 73-121.

Egido, T. (1979): "El regalismo y las relaciones Iglesia-Estado en el siglo XVIII", García Villoslada, dir., Historia de la Iglesia en España, tomo IV, Madrid, Biblioteca de Autores Cristianos, pp. 123-249.

Egido, T., coord. (2004): Los jesuitas en España y en el mundo hispánico, Madrid, Marcial Pons, 2004.

Enríquez Agrazar, L. (2006): De colonial a nacional: la carrera eclesiástica del clero secular chileno entre 1650 y 1810, México, Instituto Panamericano de Geografía.

Felices de la Fuente, M. (2012): La nueva nobleza titulada de España y América en el siglo XVIII (1701-1746). Entre el mérito y la venalidad, Almería, Editorial Universidad de Almería.

Fernández Terricabras, I. (2001): "Al servicio del rey y de la iglesia: el control del episcopado castellano por la Corona en tiempos de Felipe II", en Lo conflictivo $y$ lo consensual en Castilla: sociedad y poder político, 1521-1715: homenaje a Francisco Tomás y Valiente, pp. 205-232.

Ghirardi, M. y A. Irigoyen López, dirs. (2016): Nuevos tiempos para las familias, familias para los nuevos tiempos. De las sociedades tradicionales a las sociedades burguesas: perspectivas comparadas entre Argentinay España, Córdoba, Ediciones del boulevard.

González Cuerva, R. y A. Koller (2017): “Photography of a Ghost: Factions in Early Modern Courts", en R. González Cuervay A. Koller, eds., A Europeo of Courts, a Europe of Factions. Political groups at early modern centres of power (1550-1700), Leiden, Brill, pp. 1-19.

González de Riancho Colongues, A. (2001): El linaje de los Riva-Herrera en la Historia de Santander (siglos XVI al XX), Santander, Centro de Estudios Montañeses.

Guerrero Elecalde, R. (2011): Las élites vascas en el gobierno de la monarquía borbónica: redes sociales, carreras y hegemonía en el siglo XVIII (1700-1746), Vitoria-Gasteiz, Universidad del País Vasco.

Guillamón Álvarez, F.J. “La monarquía bihemisférica de los Borbones en el siglo XVIII. ¿La construcción de 
una empresa común?”, Reformismo en los límites del orden estamental, Murcia, Universidad de Murcia, 2010, pp. 369-380.

Iglesia Ortega, A. (2011): “Sociología capitular: el ejemplo del Cabildo de la Catedral de Santiago de Compostela en el siglo XVI", Obradoiro de Historia Moderna, 20, pp. 387-407.

Jedin, H. (1978): Manual de la Historia de la Iglesia. La iglesia en tiempos del Absolutismo y la Ilustración, vol. VI, Barcelona, Herder.

Kamen, H. (2010): Felipe V. El rey que reinó dos veces, Madrid, Planeta.

Lara Villodres, A. (2007): El marquesado de Campo Alegre, Málaga, Fundación Unicaja.

León Sanz, V. (2002): “La llegada de los Borbones”, en R. García Cárcel, coord., Historia de España siglo XVIII. La España de los Borbones, Madrid, Cátedra.

López Arandia, M. A. (2013) “Velando por el ánima del rey católico. Gabriel Bermúdez, confesor de Felipe V (1723-1726)", en J. Martínez Millán, et. al, cords., La corte de los Borbones: crisis del modelo cortesano, vol. I, Madrid, Polifemo, pp. 255-278.

López Arandia, M. A. (2015): "Clérigos y cortesanos. Balance y nuevas perspectivas metodológicas para el estudio de un grupo de poder en la Edad Moderna”, en O. Rey Castelao y F. Suárez Golán, F., eds., Los vestidos de Clío, Santiago de Compostela, Universidad de Santiago de Compostela, pp. 1129-1146.

Martín Marcos, D. (2011): El Papado y la Guerra de
Sucesión española, Madrid, Marcial Pons.

Martínez López-Cano, M. P. (2017): La Iglesia, los fieles y la Corona. La bula de la Santa Cruzada en Nueva España, 1574-1660, México, UNAM-Instituto de Investigaciones Históricas.

Martínez Millán, J. (2013): “La evaporación del concepto de "Monarquía Católica": La instauración de los Borbones”, en Martínez Millán et al., cords., La corte de los Borbones: Crisis del modelo cortesano, Madrid, Polifemo, pp. 2143-2196.

Martínez Millán, J. et al. (2011): Religión, política y tolerancia en la Europa Moderna, Madrid, Polifemo.

Mazín, Ó. (1996): El cabildo catedral de Valladolid de Michoacán, Zamora, El Colegio de Michoacán.

Mazín, Ó. (2012): “Representaciones del poder episcopal en Nueva España (siglo XVII y primera mitad del siglo XVIII)", en O. Mazín, ed., Lasrepresentaciones del poder en las sociedades hispánicas, México, El Colegio de México, pp. 373-402.

Mendiburu, M. (1876): Diccionario histórico-biográfico del Perú. Parte primera, T. II, Lima, Imprenta de J. Francisco Solís.

Moreno Cebrián, A. y N. Sala i Vila (2004): El Premio de ser Virrey. Los intereses públicos y privados del gobierno virreinal en el Perú de Felipe V, Madrid, CSIC.

Morgado García, A. (1989): Iglesia y sociedad en el Cádiz del siglo XVIII, Cádiz, Servicio de Publicaciones Universidad de Cádiz. 
Morgado García, A. (2000): Ser clérigo en la España del Antiguo Régimen, Cádiz, Servicio de Publicaciones Universidad de Cádiz.

Morgado García, A. (2007): "El clero en la España de los siglos XVII y XVII. Estado de la cuestión y últimas tendencias", Manuscrits, 25, pp. 75-100.

Nieva Ocampo, G. (2016): "Vasallo del rey y pastor de su iglesia: Melchor Marldonado de Saavedra, obispo del Tucumán (1632-1661)" en G. Nieva Ocampo et al., cords., El príncipe, la corte y sus reinos. Agentes y prácticas de gobierno en el mundo hispano (ss. XIV-XVIII), San Miguel de Tucumán, UNT.

Orrego González, F. (2017): La administración de la conciencia real. Manuales para confesar y tolerancia cultural en tiempos de la Ilustración ibérica. Siglo XVIII, Madrid, Doce Calles.

Pastells, P. (1946): Historia de la Compañía de Jesús en la provincia del Paraguay según los documentos originales del Archivo General de Indias, Vol. VI, Madrid, CSIC.

Ponce Leiva, P. y Amadori, A. (2008): "Redes sociales y ejercicio del poder en la América Hispana: consideraciones teóricas y propuestas de análisis", Revista complutense de Historia de América, 34, pp. 15-42. y I. Sanz Sancho, La época medieval: Iglesia y cultura, Madrid, Istmo, pp. 145-207.

Sartori, G. (1999): "Comparación y método comparativo”, en G. Sartori y L. Morlino, comps., La comparación en las ciencias sociales, Madrid, Alianza, pp. 29-49.

Sierra, V. (1957): Historia de la Argentina, T. 1700-1800, Buenos Aires, Unión de Editores Latinos.

Sigüenza Tarí, J. F. (1997): “La consecución del Patronato Real en España. El penúltimo intento (1738-1746)", Revista de Historia Moderna, 16, pp. 99-110.

Tedesco, E., et al. (2005): “El Cabildo Catedralicio de Santiago del Estero. Estructura eclesiástica y conformación histórica (siglo XVII)”, en S. Palomeque, dir., Actas del Cabildo Eclesiástico. Obispado del Tucumán con sede en Santiago del Estero 1752-1667, T. I, Córdoba, Ferreyra Editor, pp. 25-43.

Vidal, J. J. y E. Martínez Ruiz (2001): La política interior y exterior de los Borbones, Madrid, Itsmo.

Von Wobeser, G. (1999): Vida eterna y preocupaciones terrenales. Las capellanías de misas en la Nueva España, 1700-1821, México, UNAM.

Sallés Vilaseca, N. (2018): "Los secretarios del despacho y el consejo de gabinete de Felipe V: Diseños de una nueva planta en la administración central (17011717)”, Magallánica. Revista de Historia Moderna, 5 (9), pp. 7-38.

Sanz Sancho, I. (2002): "La Iglesia poslateranense. Expansión y vitalidad religiosa”, en J. M. Nieto Soria 